\title{
Potentials of Selected Malaysian Biomasses as Co- Gasification Fuels with Oil Palm Fronds in a Fixed-Bed Downdraft Gasifier
}

\author{
Mohamad Nazmi Zaidi Moni ${ }^{1, a}$, Shaharin Anwar Sulaiman² and Suhaimi Hassan ${ }^{3}$ \\ 1, 2, ${ }^{3}$ Mechanical Engineering Department, Universiti Teknologi PETRONAS, Bandar Seri Iskandar, \\ 31750 Tronoh, Perak, Malaysia.
}

\begin{abstract}
Oil palm frond (OPF) has been successfully gasified to produce syngas and has since deemed as a potential source of biomass fuel in Malaysia. However, if OPF is to be utilized as a main fuel for industrial-scale firing/gasification plant, interruption in fuel supply may occur due to numerous reasons, for instance inefficient fuel processing and ineffective transportation. A secondary supporting solid fuel is therefore necessary as a partial component to the main fuel in such cases, where the secondary fuel is combusted with the main fuel to adhere to main fuel shortage. Gasification of two fuels together, known as co-gasification, is practiced worldwide, some in industrial scale. However, current practice utilizes biomass fuel as the secondary fuel to coal in co-gasification. This investigation explores into the feasibility of co-gasifying two biomass fuels together to produce syngas. OPF was chosen as the primary fuel and a selection of Malaysian biomasses were studied to discover their compatibility with OPF in co-gasification. Biomass selection was made using score-and-rank method and their selection criteria are concisely discussed.
\end{abstract}

\section{Introduction}

From previous work, it was observed that biomass gasification of oil palm fronds (OPFs) has a good potential as biomass fuel to produce syngas [1\&2]. Besides, a preliminary analysis on the feasibility of OPF as well as the properties of the syngas from the gasification process was analyzed [3\&4]. In this work, the concept of a co-gasification reactor (oil palm waste and other biomass) is introduced to avoid dependencies on either fuel source and to increase the total amount of power generation. In order to ensure an uninterruptable operation in power plant from OPF fuel shortage, a secondary fuel component may need to be combined with OPF to reduce the dependency on OPF alone in a process known as co-gasification. The secondary fuel component may be processed from other biomasses that are also available in large quantities or, in small quantities but not negligible, in which they appear too little for any means of industrial utilization but co-gasification may be a golden opportunity. While many co-gasification tests have been carried out using biomass-coal mix, the proposed biomass-biomass mix has yet to be investigated, ergo, signifying the novelty in this proposed study. In comparison with related works in biomass co-gasification, no known work

\footnotetext{
${ }^{a}$ Corresponding author: nazmizaidi@yahoo.com
}

This is an Open Access article distributed under the terms of the Creative Commons Attribution License 2.0, which permits unrestricted use, distribution, and reproduction in any medium, provided the original work is properly cited. 
involving OPF has been carried out, therefore adding another challenge in this study. From the engineering research perspective this scenario needs to be explored and developed. This work proposes to extend the idea of single fuel gasification reactor to a dual fuel system whereby the reactor can operate with a flexible proportion of combined fuel in the event one of fuel sources experiences a shortage or in abundance. The general objectives of this research are to identify and to conduct investigations on biomasses that are feasible to be co-gasified with OPF in a downdraft gasifier to produced synthesis gas. A score-and-rank method was used to assign a grade to each identified biomass in terms of potentials as a co-gasification fuel.

\section{Potential biomasses for co-gasification with OPF}

\subsection{Biomass Selection Characteristics}

Biomasses were selected based on certain characteristics: morphology, $\mathrm{C} / \mathrm{H}$ ratio, calorific value, moisture content, supply and accessibility, and process requirements based on the specification of a $30 \mathrm{~kW}$ downdraft gasifier at Universiti Teknologi PETRONAS. The gasifier is known to have worked efficiently with biomass fuels with the following characteristics:

- Morphology: high density, woody to fibrous biomass fuel with minimum crisscross dimension of $25 \mathrm{~mm}$;

- $\mathrm{C} / \mathrm{H}$ ratio: elemental $\mathrm{C} / \mathrm{H}$ ratio within the range of that of general biomass, around 10

- Calorific value (CV): biomass fuel with high $\mathrm{CV}$ is more preferable to generate syngas of high $\mathrm{CV}$;

- Moisture content (MC): reduced to $30 \%$ and lower, best at equilibrium moisture content of 10$15 \%$;

- Supply and accessibility: biomass with production amount and easy accessibility is preferable to ensure steady supply of fuel to gasifier and seasonal biomass is less preferable;

- Processing requirement: biomass that requires less processing (drying, size reduction, densification etc.) has the higher advantage as a potential solid fuel due to less time and cost invested in processing

Generally, biomass with low moisture content (30\% and lower), moderate particle size (an acceptable size of 10 to $50 \mathrm{~mm}$ in dimension), high bulk density (for higher energy density) and able to resist decomposition has the advantage as a potential source of solid fuel with respect to gasification.

\section{Results and Discussions}

\subsection{Biomass Characteristics}

The oil palm trunk (OPT), empty fruit bunch (EFB), palm mesocarp fiber (PMF) and palm kernel shell (PKS) were reviewed for their potentials and compatibility for co-gasification with OPF. The chemical compositions, calorific values, and proximate analyses, CV and produced amount of the chosen biomass are shown in Table 1. All biomasses were found to have a carbon content range of 38 -50 wt. \% and a hydrogen content range of above 5 wt. \%. PKS was found to have the highest carbon content at 49.65 wt. \% while paddy straw the lowest at 33.48 wt. \%. Sawdust has the highest hydrogen content at 6.50 wt. \% and OPT has the lowest at $5.09 \mathrm{wt}$. \%. The carbon contents of the selected biomasses were found to be within that of super-compliance sub-bituminous and lignite coal (in between $35-50 \mathrm{wt} . \%$ ) at as-received condition [5]. The hydrogen contents of the selected biomasses were also found to be comparable to that of the same types of coal at $2-4 \mathrm{wt}$. \% at as-received condition. The nitrogen and sulfur contents of the selected biomasses were discovered to be 
comparable to low-rank coal as well. With the exception of OPT, paddy straw and EFB, all biomasses have nitrogen content of lower than $1.0 \mathrm{wt}$. \%. The higher amount of nitrogen in OPT, paddy straw and EFB was fairly due to the usage of nitrogen-rich fertilizers in oil palm and rice plantation that is localized for plant growth and crop production. Except for PMF, all biomasses have sulfur content of lower than $0.5 \mathrm{wt} . \%$. The relatively low contents of nitrogen and sulfur in the selected biomasses compared to coal may contribute to low emissions of the corrosive oxides of sulfur and nitrogen (NOx, SOx) from their combustion and thus require a less yield gas cleaning system, thus making the biomasses favorable as fuels for general combustion application. The $\mathrm{CV}$ range of the selected biomasses was found to be in between $13.8-20.5 \mathrm{MJ} / \mathrm{kg}$ which is within the range of that of supercompliance coal and lignite coal of in between $15-20 \mathrm{MJ} / \mathrm{kg}$ at as received condition. PKS and sawdust, being the only hardwood-like biomasses in the selection, have the highest CV at $20.40 \mathrm{MJ} / \mathrm{kg}$ and $20.45 \mathrm{MJ} / \mathrm{kg}$ respectively while fibrous paddy straw has the lowest $\mathrm{CV}$ at $13.74 \mathrm{MJ} / \mathrm{kg}$. Overall, all biomasses but paddy straw, rice husk and bagasse were found to have higher CVs than that of OPF and are favorable for co-gasification with OPF, with respect to energy content considerations.

Table 1: Elemental components and calorific values (CV) of Malaysian biomasses [6-8]

\begin{tabular}{|c|c|c|c|c|c|c|c|c|c|c|c|}
\hline \multirow{2}{*}{ Type } & \multicolumn{4}{|c|}{ Proximate analysis, wt. $\%$} & \multicolumn{5}{|c|}{ Elemental Components, wt. \% } & \multirow{2}{*}{$\begin{array}{c}\mathrm{CV}, \\
\mathrm{MJ} / \mathrm{kg}\end{array}$} & \multirow{2}{*}{$\begin{array}{l}\text { Amount, } \\
\text { Mton/year }\end{array}$} \\
\hline & $\mathrm{FC}$ & $\mathrm{VC}$ & $\mathrm{MC}$ & Ash & $\mathrm{C}$ & $\mathrm{H}$ & $\mathrm{N}$ & $\mathrm{S}$ & $\mathrm{O}$ & & \\
\hline Rice Husk & 18.03 & 50.97 & 13.08 & 0.44 & 38.74 & 5.83 & 0.55 & 0.06 & 93.56 & 14.97 & 0.44 \\
\hline $\begin{array}{l}\text { Paddy } \\
\text { Straw }\end{array}$ & 9.22 & 59.97 & 8.47 & 0.78 & 33.48 & 6.01 & 1.46 & 0.15 & 92.38 & 13.74 & 0.78 \\
\hline Bagasse & 15.91 & 80.19 & 52.20 & 0.12 & 42.93 & 5.82 & 0.68 & 0.06 & 93.44 & 15.25 & 0.12 \\
\hline EFB & 9.89 & 84.61 & 66.26 & 2.61 & 40.73 & 5.75 & 1.4 & 0.22 & 51.9 & 18.6 & 2.61 \\
\hline PMF & 11.38 & 81.52 & 45.23 & 18.74 & 40.97 & 5.93 & 0.77 & 0.51 & 51.82 & 18.66 & 18.74 \\
\hline OPF & 12.91 & 83.19 & 71.43 & 6.31 & 42.1 & 5.46 & 0.7 & 0.13 & 51.91 & 15.59 & 6.31 \\
\hline OPT & 11.42 & 76.84 & 75.90 & 4.19 & 40.64 & 5.09 & 2.15 & 0 & 53.12 & 17.27 & 4.19 \\
\hline PKS & 14.87 & 81.03 & 17.50 & 6.41 & 49.65 & 6.13 & 0.41 & 0.48 & 43.33 & 20.4 & 6.41 \\
\hline Sawdust & 16.20 & 78.80 & 16.30 & $>1.0$ & 47.2 & 6.5 & 0 & 0 & 46.3 & 20.45 & $>1.0$ \\
\hline
\end{tabular}

Note: FC: fixed carbon; VM: volatile matter; $\mathrm{MC}$ : moisture content; $\mathrm{CV}$ : calorific value

Fixed carbon is the amount of solid carbon left after a solid fuel undergoes full devolatilization and acts as the main heat generator during combustion [9]. Commonly, biomass fuels have a fixed carbon content range of $10-30 \mathrm{wt}$ \% [10]. The proximate analyses of the selected biomasses showed that all but paddy straw and EFB have fixed carbon contents of above $10 \mathrm{wt}$ \% with rice husk being the highest at 18.03 wt. \%. High volatile contents were observed where all biomasses have more than 70 wt. \% of volatiles except for rice husk (50.97 wt. \%) and paddy straw (59.97 wt. \%), which are still not so far off from average. Volatile matter refers to the components of carbonaceous fuel (except moisture) that are liberated in gaseous form at high temperature in the absence of air, mostly heavy hydrocarbons and aromatics, that are important elements for further thermochemical processes to form syngas. Amount of volatile matter proportionately helps in easier ignition of fuel [9]. High volatile contents were observed where all biomasses have more than $80 \mathrm{wt}$. \% of volatiles except for OPF (76.84 wt. \%) and sawdust (78.8 wt. \%), which are still not so far off. The volatile contents of the selected biomasses were also found to be higher than that of coal which commonly is in the range of $30-40$ wt. $\%$. 
For combustion purposes, only $30 \%$ and below moisture content in fuel is deemed acceptable. All biomasses have as-received moisture content of more than $30 \%$ except for PKS, paddy straw, rice husk and sawdust, mostly due to their small particle size that makes drying easier and their hardwood properties that stores less moisture than fibrous structure does. This means that all biomasses with more than $30 \%$ as-received moisture content need to undergo drying process to keep their optimal properties and to maintain their quality as solid fuel prior to being utilized for combustion. The ash contents for all biomasses were below $10 \mathrm{wt}$. \% except for rice husk and paddy straw that were the highest at 22.0 wt. \% and $18.3 \mathrm{wt}$ \% respectively, and generally were comparable to that of coal. Low ash content signifies lower risks of slagging due to accumulation of molten ash from exposures to high temperature during combustion and consequently lower risks of reactor operation problems [10]. Also, low ash content implies a lesser space and handling needed to manage ash storage and removal.

\subsection{Supply and Availability}

Other than OPT, OPF and paddy straw, all the biomasses are available as processed biomass byproducts at respective processing mills. Residue biomasses such as OPT, OPF and paddy straw are available at their respective plantation origin, mostly from harvesting and felling. Most paddy and oil palm plantations in Malaysia are easily accessible using land vehicle and this eases the transportation of biomass out from the plantations using bulk carrier vehicles, although some plantations may not be spared with modern road access. As for mill refuse biomasses, they can be collected in-situ, commonly in crushed and ground forms. Most processing mills are located near to modern road and facilities, and are easy to access. In terms of availability, OPF tops the list with more than 18.7 Mton/year supply, followed with EFB, PMF, PKS and OPT, in that order, for oil palm-derived biomasses. Sawdust was estimated to be produced at more than 1 Mton/year while rice husk, paddy straw and bagasse were produced at less than 1 Mton/year. Rice husk, paddy straw, bagasse and OPT are produced seasonally, therefore their amounts only peak at harvesting and felling (for OPT) period, and is a disadvantage in creating a continuous biomass fuel supply throughout the year from these sources. However, with proper processing and storage, they could withstand a longer storing time for out-of-season utilization.

\subsection{Potential Biomass Score and Rank}

Score and rank method was used to select the biomass fuel sources using their potentials based on the discussed selection criteria. A simple ranking method was used to sort the biomasses from the most to less favorable as biomass fuel for co-gasification with OPF using their attributes. Eight main attributes were used for the ranking process: volatile content, moisture content, calorific value, annual production, supply availability, drying requirement and briquetting/densification requirement. Biomasses with high volatile content, high calorific value, large amount of annual production, highly available, low moisture (therefore low requirement for drying) and large particle size (eliminates the need for briquetting/densification) are highly favorable as co-gasification fuel with OPF. The results of the ranking process are shown in Table 2. From the results it was discovered that herbaceous biomass such as bagasse, rice husk and paddy straw scored the lowest compared to fibrous and woodlike biomass. PKS tops the list for it fulfilled all the preferred criteria as biomass fuel, followed with PMF, sawdust, EFB and OPT.

\section{Conclusion}

Potential biomasses for fuel production to be used in co-gasification with OPF were reviewed and ranked. It was found that most Malaysian biomasses are eligible to be used as fuel, provided that they undergo certain processing methods in order to become solid fuels that are optimized for downdraft co-gasification process. With this preliminary data, further detailed analyses can be carried out to 
study the fuel compatibility in gasification and their gasification yields. Overall, the objectives of the preliminary study were met and the results were positively viewed as a constructive progress in this particular research.

Table 2: Ranking of selected biomass based on selection criteria

\begin{tabular}{|l|c|c|c|c|c|c|c|c|c|c|}
\hline Type & VM & MC & CV & C/H & AP & SA & DR & BD & Score & Rank \\
\hline PKS & 6 & 6 & 8 & 9 & 6 & 1 & 0 & 0 & 36 & 1 \\
\hline PMF & 7 & 5 & 7 & 3 & 8 & 1 & 1 & 0 & 32 & 2 \\
\hline OPF & 8 & 2 & 4 & 7 & 9 & 1 & 1 & 0 & 32 & - \\
\hline Sawdust & 4 & 7 & 9 & 5 & 4 & 1 & 0 & 1 & 31 & 3 \\
\hline EFB & 9 & 3 & 6 & 4 & 7 & 1 & 1 & 0 & 31 & 4 \\
\hline OPT & 3 & 1 & 5 & 8 & 5 & 0 & 1 & 0 & 23 & 5 \\
\hline Bagasse & 5 & 4 & 3 & 6 & 1 & 0 & 1 & 0 & 20 & 6 \\
\hline Rice Husk & 1 & 8 & 2 & 2 & 2 & 0 & 0 & 1 & 16 & 7 \\
\hline
\end{tabular}

\section{References}

1. M. N. Z. Moni and Shaharin A. Sulaiman, "Development of a Biomass Downdraft Gasifier for Oil Palm Fronds", In National Post-Graduate Conference (NPC), (2009)

2. S. A. Sulaiman, S. M. Atnaw and M. N. Z. Moni,"A Preliminary Study of Oil Palm Fronds for Gasification Process". In Power and Energy Systems (EuroPES 2011), 22-24,Crete, Greece. (2011)

3. M. N. Z. Moni and S. A. Sulaiman, "A Preliminary Study on Synthesis Gas Produced by Gasification of Oil Palm Fronds," In International Conference on Plant Equipment and Reliability (ICPER), Kuala Lumpur. (2010)

4. S. A. Sulaiman, S. Balamohan, M. N. Z. Moni, S. Mekbib and A. O. Mohamed, "Study on the Feasibility of Oil Palm-Fronds for Biomass Gasification”, In 5th International Ege Energy Symposium and Exhibition, Denizli, Turkey. (2010)

5. NETL, "Quality Guidelines for Energy Systems Studies: Detailed Coal Specifications," The Energy Lab, U.S. Department of Energy (2012).

6. Malaysia APEC Energy Demand and Supply Outlook, (2006) Available at: http://www.ieej.or.jp/aperc/2006pdf/OOutlook2006//ER_Malaysia.pdf

7. Malaysian-German Chamber of Commerce, "Market Watch 2008- The Environmental Sector in Malaysia”, (2008) Available at:http://www.mgcc.com.my/fileadmin/user_upload/Dokumente /Sektorreports/Environment_E_08.pdf

8. S. S. Abdullah and S. Yusup, "Method of Screening of Malaysian Biomass Based on Aggregated Matrix for Hydrogen Production through Gasification,” Journal of Applied Sciences 10 (24): 3301$33016(2010)$.

9. UNEP, “Thermal Equipment: Fuels and Combustion," Energy Efficiency Guide for Industry in Asia, available at: www.energyefficiencyasia.org, (2013)

10. SERI, "Handbook of Biomass Downdraft Gasifier Engine Systems," Report Number SERI/SP271-3022-DE88001135, U.S. Department of Energy (1988). 